\title{
An Effective Models for Organizational Change in Bureau Veritas, London: Case Study
}

\author{
KATEŘINA BOČKOVÁ \\ DTI University, Dubnica nad Váhom, Slovakia \\ Email: bockova@dti.sk \\ Tel: +421905692227 \\ KAROLINA LACHI KOLAROVA \\ Bureau Veritas UK, London, United Kingdom \\ Email: karolina.lachi-kolarova@uk.bureauveritas.com \\ Tel: +421905692227 \\ DANIEL LAJČIN \\ DTI University, Dubnica nad Váhom, Slovakia \\ Email: lajcin@dti.sk \\ Tel: +421905692227
}

\begin{abstract}
In the fast moving globalized world, we are living in; change has become a must for organizations to drive their success and keep existing. Many authors have defined various definitions and methods how to manage organizational change; however the success rate for significant organizational change is quite low, only $30 \%$ of all change initiatives are successful, this is a meagre number. This paper is focused on successful models for organizational change. The research was focused on to analyse organizational change to establish: Provide a review and summary. Deliver an analysis. Develop measures of successful change. Verify the underlining factors. For that reason, the research was designed to use a combination of a qualitative and quantitative approach to collect data using surveys and personal interviews. The paper explores some of the common models that organisations adopt when implementing organisational change. Whilst organisations can (and often do) implement change without referencing any established model we wanted to improve our understanding of the key aspects that are important to ensure were in place before implementing an effective change project.
\end{abstract}

Keywords: Organizational Change, Organizational Change Model, Project.

\section{Introduction}

In the fast-moving globalized world, we are living in; change has become a must for organizations to drive their success and keep existing. Many authors have defined various definitions and methods how to manage organizational change; however, the success rate for significant organizational change is quite low, only $30 \%$ of all change initiatives are successful, this is a meagre number. Most recently Rous (2011, p. 71-92) recognizes that this rate is not improving, which raises a question for further research and investigation.

The top reason changes initiatives failing is something called change fatigue means too many change initiatives without prioritization. The second reason is the CEO and his/ her top team just dictating what should change, and what is this change program about and this doesn't work very often. The organization 
can become passive aggressive and wait until the CEO or executive team changes before they activate a change. The biggest mistake sponsor makes thinking that communication is the same as engagement. They are very different and both are incredibly important. The impact of poor organizational change management is; first you don't achieve the desired results, second, you wasted loads of resources such as time, people and money. And lastly and maybe the most important you are typically left with diminished morale and reduced performance.

The other thing changes managers do, believe that communications, training and changing reward systems is enough to move an organization to a new place (Torbenrick 2018). For an organization to be successful with their change journey, it requires to follow a structured and clear method (Haidar, 2006, p. 13). The organizational change management literature offers a considerably different view on what's the most appropriate method for managing organizational changes (Bamford \& Forrester, 2003, p. 546). As stated, change affects all parts of an organization, from strategy to internal structure their processes, people's jobs and attitudes but importantly organizational culture needs to recognize the difference this at times can be a somewhat challenging process (Kanter, Stein \& Jick, 1992). Dunphy \& Stace (1993) view is that management needs a model of change that is situational. A model that enable to change strategies to achieve the best fit. In the same way as Bamford \& Forrester (2003) or Dunphy \& Stace (1993) argued organizations need a change method that can be modified to with organizational environment.

Culture is critical to the success of change management programs. Most change programs deal very effectively with the formal aspects of an organisation; this can be things such as decision rise, process flows, and structure or performance management system (Habib \& Wazir, 2012). But the definition of culture is how things get done within the organization. And that is much influenced by the formal aspects as it forms how employees think, what they believe, how they act and feel. So, you have to deal with the cultural aspects, or you won't impact the change the way you want.

Sponsors should address culture by first focusing on the culture leavers what is in the culture that can actually help them and make them feel proud about what they need to do. It's an asset that in the organizations, that it's rarely used. Second, use the power of Special Forces, they are the informal leaders in the organization sometimes they have a management position, but sometimes they don't, but those people are trusted and motivate others, and they take pride in what they do. Lastly, it's essential to create an environment that it's called coherence which means that anyone in the organization understands what they need to do without being told what to do.

The ideal change management team should have multiple entities engaged firstly CEO his or her leadership team they not only need to understand the program, but they also need to start acting in different ways that are visible to the rest of the organization. We also need the respected leaders again showing they will do things differently and it's critical to identify and engage everybody impacted by the change including the front line employees, team members usually people who face the customers it's incredibly important they are part of this change team. Lastly critical are the culture and change experts they need to be there operate as counsellors to ensure the program happens and give the expert advice.

Research of fair process has shown that the outcome is not the only factor employee's care about, but also the process that produces the result. In fair process methodology, people affected must have the opportunity to give input and suggestions or options however the process must be transparent. Research has shown clearly that a fair process has a significant and positive impact on both performance execution and employee motivation. However, work to date has not addressed why a fair process is so often violated in practice.

This paper is focused on successful models for organizational change. 


\section{Literature Review}

We always lived in a world that is constantly changing, however, the frequency and scale of change with today's technology are increasing. Therefore, a change has become the new norm for organisations to sustain their success and guarantee an existence. All organisations including governmental and industrial continuously aligning their operations with a changing environment, as cited in Ackoff (2006), Burnes (2004), Balogun \& Hope Hailey (2004), Kotter (1996), Habib, Jamal \& Manzoor (2018a) or Moran \& Brightman (2001). We also see a shift in strategic importance; effective managing mass markets, innovation or knowledge management, to which their leaders naturally respond (Dess \& Picken, 2000, p. 18-34).

Organizations need an integrated approach to drive a change in a systematic and constructive manner, which will not cause destructions to their operations. However, organisations still face a high failure rate in regards to organisational change initiatives. Organisations understand that any organisational change requires planning and engagement (Habib, Jamal, \& Manzoor, 2018b). Successful change management became a key top for an organisation, especially during the recession, as Ashurst \& Hodges (2010. P. 217237) say.

This section is focused on a review of the history of change and reviews main authors that have over the years analysed the three main contributing disciplines of change namely:

1) Management and leadership,

2) Sociology and psychology,

3) Engineering management (EM and industrial engineering (IE)).

Research in a change with respect to psychology and sociology started with Lewin. Lewin is considered the intellectual father of the philosophies of organizational development.

The discipline of management was first introduced by Fayol (1950) as part of general administration and become a major focus of research. Fall is also recognised for developing the fourteen principles of management. Fayol also separated administration functions into five elements:

1) Planning,

2) Organizing,

3) Commanding,

4) Controlling,

5) Coordinating.

Drucker (1986) in 1974 defined management as a process of completing tasks with the support of other resources. He urges that business has to be managed by balancing the different company goals and objectives and created a term called "management by objectives".

In 2004, Winston argued that leadership can be defined as a process where a person influences and directs others to accomplish a shared objective and goal. Servant leadership is based on a timeless concept. First, the phrase was used by Greenleaf. In that essay, Greenleaf said: "The servant-leader is a servant first... It begins with the natural feeling that one wants to serve, to serve first. Then conscious choice brings one to aspire to lead. That person is sharply different from one who is the leader first, perhaps because of the need to assuage an unusual power drive or to acquire material possessions...The leader-first and the servant-first are two extreme types. Between them, there are shadings and blends that are part of the infinite variety of human nature"..."The difference manifests itself in the care taken by the servant-first to make sure that other people's highest priority needs are being served. The best test, and difficult to administer, is: Do those served grow as persons? Do they, while being served, become healthier, wiser, freer, more autonomous, 
more likely themselves to become servants? And, what is the effect on the least privileged in society? Will they benefit or at least not be further deprived?"

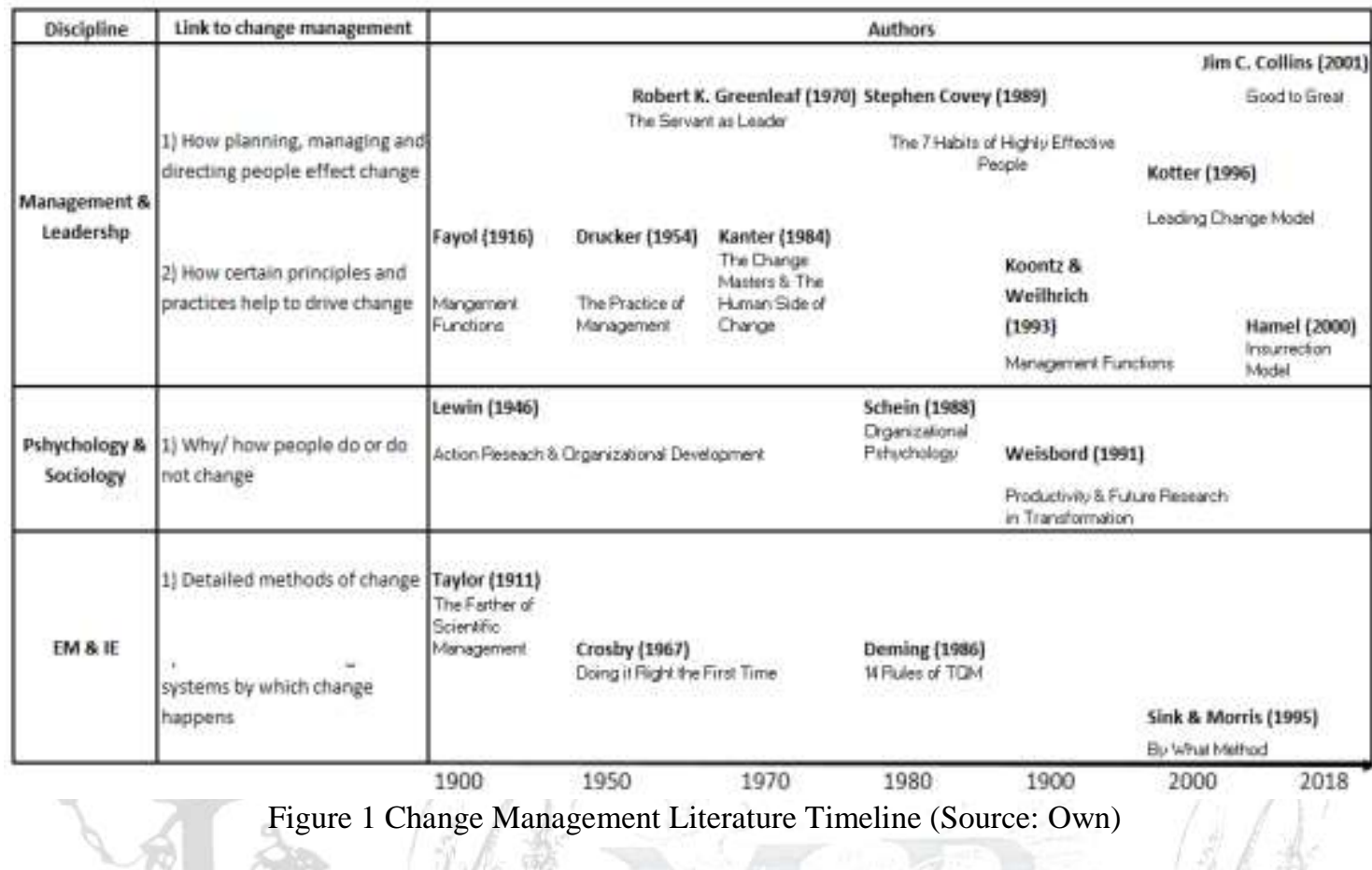

Primarily focus on servant leaders is on the growth and wellbeing of people and an environment they belong to. Where traditional leadership is exercised power by one at the top of the pyramid servant leadership is different, and it's based on the inverted pyramid approach. The servant leaders don't hesitate to share power and put the needs of others first to develop people and perform as highly as possible.

The servant leadership is quite a paradox because in top-down leadership model the workers are at the bottom supporting and lifting up the leaders who are at the top because it's about them. In servant leadership, the pyramid is inverted the leader is at the bottom supporting and lifting up the employees to help them deliver the expected benefits and advantages of the change project and also ensure that the team developed their skills and confidence. This will enable the organisation to capitalise on this learning so that improves the rate of successful change. It is important to understand that the application of servant leader it's not an embedment of accountability it is a process whereby responsibility and ownership are transferred to the team involved with the change program.

Servant leadership doesn't mean that the leader is weak the exact opposite in fact as servant leaders are very demanding as they require excellence. EM is applying engineering values and skills in coaching people and leading projects (Lannes, 2001, p. 107). Neave (1990, p. 190) always argued that it's the hands of management who drive quality improvement. He was able to demonstrate that most problems are the results of the system and not of people. To demonstrate that he used statistical quality control techniques to show special and common cause conditions. Where common cause was driven by systematic variability when the special cause was one off and unpredictable. Over the years it has been found that Neave's philosophy is a very powerful guide to build a long-lasting system that makes companies more efficient and competitive.

In IE, mainly five authors provide insight into change management methods: Neave (1990), Juran (1962), Crosby (1984) and Sink, Shewhart (1985). Shewhar \& Deming (1945) first improved the traditional 
production process and looked at it as a scientific method. The steps involved were: specification, production and inspection. He later converted this principle into a cyclical concept, what is today known as the Shewhart cycle.

In 1985, Sink (1985) completed research on productivity and productivity management. He introduced evolutionary strategies and new techniques that are used for developing measures in organisations. It was Sink \& Tuttle (1985) who introduced the "performance improvement planning process" and created a roadmap for converting an organization into "the organization of the future" where organisational performance is improved using effective measurement systems. They created seven performance measures:

1) Effectiveness,

2) Efficiency,

3) Quality,

4) Productivity,

5) Innovation,

6) Work-life balance,

7) Profitability.

After reviewing the available change management literature, we provide a glossary and classify the change management literature. The glossary of the literature is covering three main areas: change methods, which split into systematic changes and change management models, and change outcomes.

Change methods can be characterised as methodologies used by managers to deal with change and are classified into two groups: systematic change methods, and change management models. Systematic change methods use a set of processes and tools to support the management team with a series of start, stop and continue decisions (Zook, 2007, p. 6675). In the last 20 years, a number of systematic change methods have been introduced. These methods include many processes, such as diagnosing the current state, planning, communication phase and finally implementing the new change. Change theories traditionally have advocated for an incremental process adaptation and infrequent small transitions that are planned and driven by management (Thompson, 1967). In recent years new methods became more systematic, that involve larger scales of organizations changes (Bulloock \& Batten, 1985, p. 383), (Singh \& Shoura, 2006, p. 337-348). Various authors have created many systematic change methods:

- Six Steps: In 1990 Beer, Eisenhardt \& Spector (1990, p. 158-166) introduced the six-step method. The method is based on a principle of "task alignment" this can cover reorganizing employee's roles or responsibilities and is focused on a specific organizational problem. As the name indicates, this method contains six steps and is the fundamental principle is to actively involve people in problem identification as well as creating a shared goal. The writers believe by engaging individuals in the change solution it will drive a reduction in the resistance of a change.

- Wheel: Galpin (1996) has introduced this method in his book The Human Side of Change. This book was published in 1996. This method consists of define steps which are in the shape of a wheel that effectively involves people in a technical change process. He argues that the reason for organizational changes failing is because people are not taken into consideration. The first step in the wheel is establishing the need for change, followed by careful planning and implementation and importantly dealing with behavioural changes at the organization. Galpin recognizes the importance of organizational culture as well as policies and reward systems.

- Lean thinking: In the 1990s Toyota adopted lean thinking methodology which created very popular (Holweg, 2007, p. 420-437). Lean thinking is based on three principles: produce only what is needed, when it's needed and efficiently not wasting materials, equipment, labour or space. Therefore this methodology is focused on purpose, process and people (Womack \& Jones, 2003). However, the reason for their success was due to their culture. The methodology fails in other organisations as they do not have the culture that was created by the leader of Toyota. 
- Total Quality Management: TQM gained attraction in the 1950s, and eventually, its principles evolved into the Deming cycle (Plan, Do, Check and Act). Juran (1962) is known for being the father of quality, and he identified the three main aspects of quality: planning, improvement, and control. Deming is another very well-known quality guru, who created a simple, but effective technique that works as an effective tool and drives continues improvement in the organization (Moen \& Norman, 2010).

- Six Sigma: It was at Motorola in 1987 when Six Sigma was first used, and this method had a positive impact on their return on investment ever since (Mader, 2008). It is recognized that even Six Sigma has been widely used by the industry there is limited research available in the literature. Six Sigma uses very structured cyclical actions to improve organizational performance. This method uses something called DMAIC which stands for: define, measure, analyse, develop and control. This methodology is based on Deming's PDCA (Linderman, Schroeder \& Choo, 2006, 779-790).

- Process reengineering is a tool which enables a user to achieve significant improvements and innovations using set performance measures: cost, quality, service, and speed. Process reengineering is associated with an aspiration to achieve, and it is aimed to add value to services or products. Processes applicable to this methodology are such as sales or internal process affecting organizational functions, whose role is understanding the problem, finding a solution and implementing the change (Habib \& Jamal, 2014).

Whilst organisations can utilise many models to assist with the change management process they often fail to understand that every model has got its limitations and advantages. They should select a relevant model after considering what is required from the change process and ensuring that it can be applied and it's relevant for that particular change. This includes what has been used before its success and failure and ensuring that it fits your organisational culture.

Lewin method (Process 2018) suggested that the first step of change starts with unfreezing the current state by creating incentives then implementing desired changes with the right leadership style and refreezing the state when the desired change has been reached. Lewin stressed the importance of dialogue when solving the problem and believe that successful problem requires an active facilitator of change.

In 1996, Kotter (1996) proposed the leading change method. His method contained eight steps. He identified the most common pitfalls that occur when organisations implementing a change and provided a solution to overcome those. His solution first focused on establishing a sense of urgency, real crises, then also building a trusted team, which support the change. Another step are to have a vision and strategy and implementing the change and account for short term wins.

\section{Creative problem solving and Fair Process}

Whilst we know that many change projects do not succeed due to the failures associated with appropriate sponsorship, planning or understanding of benefits there is one component that is often overlooked. The failure to understand or apply "fair process" means that many change projects do not deliver the results that are expected despite having good Sponsorship, Resources, clarity of objectives etc. So, what is "fair process?" (And what it isn't) (Kim \& Mauborgne, 1997).

1. Engagement: This means asking people who would be affected by the change for their input. It also requires clarity regarding the reasons for change and what the goal of the change is. It is important that individuals know that their input will be evaluated without fear or favour. Unless contributors feel that their ideas and input will be received equally "Engagement" will be superficial and will result in poor

2. Commitment to the change when implemented. It is vital that the Project Sponsor believes that by involving people in the process will result in a better understanding of the issues and potential solutions. The research shows that by genuine engagement everybody involved in the change provides an improved commitment to the change. 
3. Explanation: This relates to ensuring everybody who has been engaged understands why a specific option has been chosen. It is not about selecting something that provides consensus or selecting the most popular idea. Managers remain responsible for making decisions, the key is to ensure those involved in the process receive feedback so that it helps their own learning and development.

4. Expectation Clarity: Once an option has been selected, it is vital that everybody involved in the change what impact it will have on how they work or the policies and procedures that they use. If new targets will be set, they must be informed. They need to be aware of how these changes will be monitored and the consequences for failing to meet the "new rules". Once "Fair Process" is understood, the implementation of this approach can depend on the attitudes and values of the Manager responsible for the change. If they do not believe that people can contribute to the development of ideas, they will either not use the approach or simply misuse the "Engagement" stage to drive the option they want. The lack of "Fair Process" can lead to situations where the people affected by the change invoke retributive justice where they ensure the change generates negative performance. CPS a model to help organisations solve problems and manage change creatively. It provides a set of easy-to-use tools to help translate an organisations goals and dreams into reality. CPS has been referred to a "Software for the Mind", the CPS v1.0 emerged from the early work of Alex Osborn, who developed the 1st version in 1952 when he was concerned that he was not getting the results he expected when he worked with a highly regarded team. Since that time, CPS has evolved by building upon theory and research from the cognitive and behavioural sciences as well as practical experience of managing Change. There have been 6 six major versions of the model with each version incorporating incremental updates and refinements (note: a change in the version number indicates a major advance, and a change in the decimal following the version number indicates a refinement of that version).

The McKinsey 7-S change model is very useful for reviewing how coherent your organisation is. And not like others supporting a deep analysis and large shifts. This model is particularly compatible for organisations which know they need to change how they act, but yet don't have a solution on how to achieve it. The process to do so is to analyse seven aspects and work out how they affect each other. You will then highlight the changes and you must create a united approach to the business.

The 7-S model will shine the light on the weaknesses in your organization and will flag areas that require the most change. Additionally, that, emphases the importance of all aspects of your organization supports each other, finally provides you with a business plan which is known for its robustness but also flexibility. The McKinsey model requires loads of detail of all aspect of an organization and as it's nearly impossible to effectively carry it out alone and in short space of time an extra time and resources are required which makes it an expensive and time-consuming.

The McKinsey 7-S model is best suited for those who want to know how they can change for the better. By creating an overview of how coherent and effective the various elements of your company are, you can then go on to analyse your current situation and draft changes to tackle the problem. In other words, this model is great if you don't know where to start, but if you are just looking to assess the viability of a specific change, it might be best to use a model which has a smaller scope (PROCESS@2018).

The ADKAR model was originally created by Jeffery Hiatt, the ADKAR change model uses a bottom-up approach which puts emphasis on the individuals that are affected by the change. This model is less methodological step by step model and more of a set of goals focused, and each of the goals is reflected in the letter of the model name acronym. To achieve an effective change it's required to focus on five goals:

1. Awareness- this stage is all about employee understanding the need for change, using proactive engagement

2. Desire- this is the most challenging part of ADKAR change method as it's covering both logical and emotional side of the employees. It's important to use real examples and listen to feedback. 
3. Knowledge- at this stage you need to make sure everyone understand how the change will be completed

4. Ability- sometimes it seems knowledge stage and ability are the same, but just because you know something doesn't mean you can do it that is what this stage to do.

5. Reinforcement- making sure that the change is embedded fully to become the new norm.

The positive thing is that ADKAR change is greatly focused on employees and provides a flexible framework, which can be applied to most of the situations. Importantly the added focus on the people and their needs rather than just a technical aspects results in higher success rate. The challenge is as it's situated for incremental changes and it's lacking the solution for large- scale alterations. The ADKAR model is a great change model cutting through any messy setups and gets straight to the point whilst improves employees' response to change.

Consequences of an organizational change are called change outcomes. Measuring outcomes can drive organizational development and success, but its necessary measurement systems are correctly developed and implemented. According to Sink and Tuttle (1989), the best measurement system is a bland of hard and soft objectives together with judgment and decision rules. Monitoring performance of outcomes can provide management with new insights as to why the company performs as it does and highlights areas which can be improved such as areas in or out of control. Setting and defining performance goals is one of the critical decisions for any organization and are part of the organizational strategy. It's essential that those are clearly defined (Gunasekaran \& Kobu, 2007, 2819-2840), (Ittner, \& Larcker 1998, 205-238), (Wouters $\&$ Sportel, 2005). Seven performance measures identified:

1. Effectiveness- measures accomplishments.

2. Efficiency-outcomes vs. resources used.

3. Quality- process capability and value.

4. Productivity- outputs vs. input.

5. Innovation- measures creativity.

6. Work-life balance- employee's conditions.

7. Profitability- budget vs. actual.

However, change outcomes are not the only measured by hard measures such as above. We also have soft measures that are often forgotten as they are hard to quantify. Grover $(199$, p. 36) completed two studies which resulted in further outcomes:

1) Improved customer service.

2) Improved cycle time.

3) Reduced cost.

4) Improved quality of product/ services.

5) Improved organizational responsiveness.

6) Improved employee morale.

7) Employees layoffs.

8) Changed the organizational structure.

Armenakis and Bedeian (1999, p. 293-315) suggest that there are four change outcomes:

1) Quality.

2) Service.

3) Productivity.

4) Risk-taking.

Nevertheless, Neves and Caetano (2009, p. 623) argue that change outcomes consist of: 
1) Organizational citizenship behaviours.

2) Perceived performance.

3) Turnover Intentions.

In response to global environment organisations and their leaders are constantly facing a challenge of change, however, the success rate remains very low. Organisational change takes time and requires good planning and to increase the success of change it's important that all critical factors are addressed. Methods available and reviewed in this chapter covered several systematic changes as well as change management methods.

\section{Research Questions}

To address the current need of organizations to have more effective methods in managing change, this research answered a specific question. The questions emerged from a research perspective.

Research question: What is an effective model for successful organizational change and is fair process methodology that is based on engagement, explanation \& expectation clarity connected to successful organizational change?

Successful change: "A change that results in a positive outcome and the desired performance" (Sink, Johnston, \& Morris, 1995), (Hamel, 2000).

\section{Methodology Used}

The research involved various phases that are broken down into steps and contained reviews the outputs of each phase. The research phases are listed as per below:

1) Review literature to gain coherent knowledge relating to the subject.

2) Identify the different types of change.

3) Create a research model: Through surveys and interviews.

4) Verify and validate stage.

5) Summarise outcomes of the surveys etc.

6) Analyse results.

7) Provide conclusion and recommendations.

This research paper methodology is based on qualitative research (Creswell \& Miller, 1997, p. 33-46). The knowledge and information gathering was completed utilising surveys and interviews. This type of research is also known as subjective and interactive (Creswell \& Brown, 1992, 41-62). This research was designed to achieve the following goals:

1) Develop a roadmap of the available literature.

2) Provide a summary of the change definitions and types.

3) Conduct surveys and interviews on change.

4) Provide summary and recommendations for successful change.

For this paper, we decided to develop a research methodology that uses a combination of qualitative and quantitative research with main characteristics:
1) Purpose.
2) Data Collection.
3) Data Analysis.
4) Results Reporting. 
The research was focused on to analyse organizational change to establish:

1) Provide a review and summary.

2) Deliver an analysis.

3) Develop measures of successful change.

4) Verify the underlining factors.

For those reason the research was designed to use a combination of qualitative and quantitative approach to collect data using surveys and personal interviews. We have used two type of sources surveys and interviews with open-ended questions. This methodology was selected based on following principles:

1) Survey research is one of the first methods used and the most widely used (Hackett, 1981). Survey definition can be explained as an investigation of specific aspects of a population by studying a sample of the given population and it's useful for collecting data that would otherwise not be available. This study analyses the details about the successful or unsuccessful models for organisational change projects.

2) Interviews are the most comment methods to collect data for qualitative research, which enables the researcher to ask further questions to obtain more meaningful information (Frels, Onwuegbuzie, 2013, p. 184-194). Interviews are particularly useful to discover the detail behind respondents' experience that can't be discussed or understood otherwise. Additionally, information collected from interviews contains more comprehensive view regards to the projects and provides further insight of change methods used and outcomes.

The survey used in this research was created to measure all aspects identified in the research question. In 1996, Kraut identified the survey process as a solution that can collect information by primarily utilizing closed-ended questions, however, open-ended questions can also be used. The information collated is then carefully processed and analysed to obtain a coherent conclusion. The survey process contains key seven actions:

1) Problem definition: at this stage is to clearly define the problem and set an objective.

2) Survey design: survey can be created either cross-sectional or longitudinal. Cross-sectional surveys tend to be used when the data required is a population at a specific point of time. Longitudinal survey at two or more times which enables assessing variation over the period.

1) Sample selection step has multiple types such as simple random sampling, systematic sampling or cluster sampling. Each of those types has its benefits and negatives.

2) Questionnaire development steps it's when the researcher formulates the questions and decides what kind of data needs to be collected.

3) Pilot testing stage obtaining initial feedback and to see if questions are understood and meet the required objective.

4) Data collection it's a stage which covers the actual data collection from respondents and can be deployed in various ways such as online, personal interviews or phone interviews.

5) Data analysis stage covers a review of information obtained from the respondents at the data collection stage and follows a quantitative approach.

The survey used in this research contains 21 questions and its split into three parts:

1) Successful organisational change.

2) Unsuccessful organisational change.

3) Open-ended Question.

The main reason for asking the sample respondents to describe two different projects (successful and unsuccessful) was to increase the size of the sample. The survey used a five-point Likert scale to determine 
how much they agree or disagree. This scale was created in 1932 by Likert. The survey five options as listed as follows:

1) Strongly agree: strongest level of agreeing.

2) Agree: agreeing with the question statement and places the majority.

3) Neither agree nor disagree: Neutral statement.

4) Disagree second lowest level of agreeing.

5) Strongly disagree with the lowest level of agreeing with the question statement.

Parts 1 and 2 were created to establish the project outcomes using a five-point scale with specific activities related to either successful change or unsuccessful change. As part of research preparation, a pilot survey was issued to a small group of participants who understand survey methods methodology. As part of a draft process of the survey, a pilot test was completed to ensure the survey would be understood by the participants and will provide the required data to analyse the research problem. The pilot survey was distributed to a group of 10 people they all were briefed what the survey is for. They were required to answer the questions and suggest any improvements or comment where the question may be unclear, finally provide an alternative suggestion. After receiving the input collated from the pilot test, minor modifications were made to the survey.

The total number of participants in the survey was 57 and it was completed using the online portal (surveymonkey.com). Further 6 respondents completed face to face interview of which 4 were men and 2 women. Three men were employees of Bureau Veritas and their roles within managing organisational change varied from facilitator to resource group and change manager. One interviewee was represented from Scottish and Sothern Energy a utility provider and in his example of organisational change he was part of a resource group and finally the two women interviewed were both sponsors within the organisational change and both were from Bureau Veritas. Their average age was 42 and with an exception of two people, they all had university degrees. Five completed surveys for successful projects and further five completed surveys completed on unsuccessful projects were discarded due to partially or incomplete response. The grand total of the sample was 52 for the successful projects and 52 for unsuccessful projects with a total of 104 undertaken surveys for both types of projects. This number of respondents to the survey meets the rule of thumb suggested by Green (1991, p. 499) that a sample size needs to be at least 50.

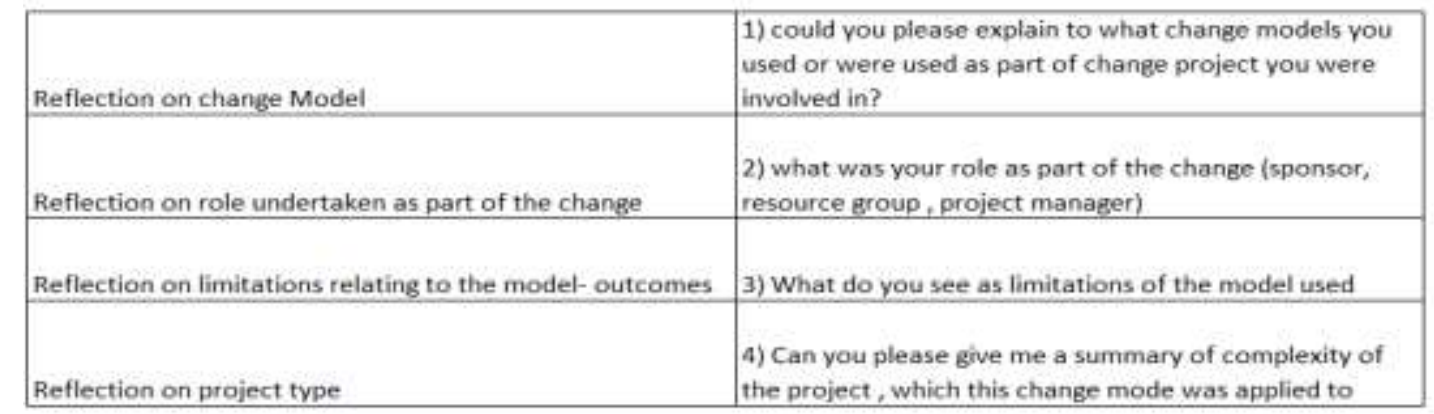

Figure 2 Interview questions (Source: Own)

This research also capitalized on written interviews to obtain further information about organisation change and the methods used in that change. In 2001, Leedy and Ormrod (2005), split interviews into different categories: unstructured, semi-structured and structured. The interviews in this research used semistructured, which are the most common type of interviews for qualitative research. This type of interviews uses pre-set questions to allow the researcher to seek further information if required. Using open-ended questions encourage participants to open up about additional information which wouldn't be obtained when using a survey. Figure 2 provides a list of the questions used. 
In 2011, Olson suggested successful interview requires detailed preparation and requires taking notes during the interview, taking time with the interview, and being mindful with sensitive subjects. This part of the paper covers general limitations associated with this research. It has been identified that generalization of the survey results is doubtful since there was no randomization of the respondents participating in the survey and interviews. More organizations can be involved to achieve greater research information and context to increase generalizability of the conclusions. Moreover, the small number of respondent limits the ability to develop general theories.

In the future, further analysis can be completed and the baseline survey created in this paper can be used to support such research with a different type of organisations to increase the sample size. An additional limitation of this research was that the questionnaire didn't include gender or demographic aspect. Despite the limitations identified, this research was able to make useful conclusions and recommendations using available literature and make a connection between the survey results and organisational change models.

\section{Theoretical Framework}

The research explored different areas that may affect organizational change. It was recognised that change combines two or more academic fields. Three main areas of Engineering Management, leadership/ management and sociology/ psychology are interconnected and essential to understanding when researching change (Figure 3 ).

The definition of leadership is communicating to people their worth and potential so clearly that they are inspired to see it in themselves (Covey, 1989). Leadership can be also defined as a process whereby an individual influences others to accomplish a specific objective or a shared goal (Northouse, 2007). Kouzes and Posner (1995) propose that the main leadership habits are: modelling the way, inspiring a shared vision, challenging the process, enabling people to act and finally encouraging the heart.

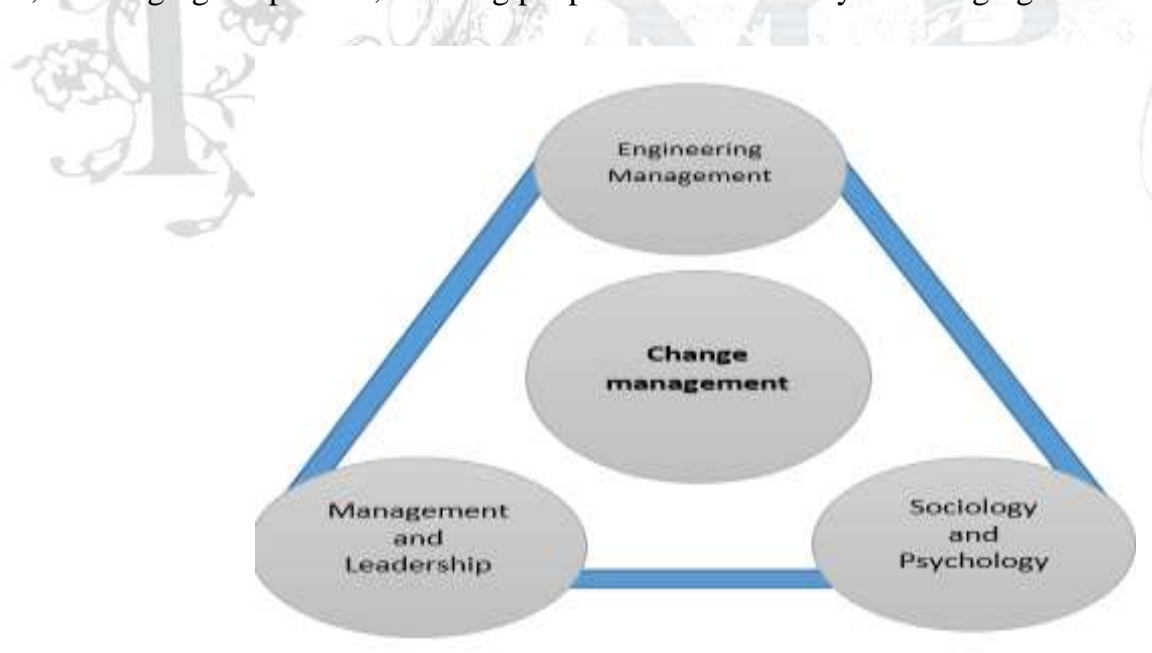

Figure 3 Relevant Areas relating to Change (Source: Own)

Collins (2011) introduced Level 5 leadership. According to him Level 5 leaders possess a strong mixture of personal humility and invincible will. It is clear they are very ambitious, but their ambition is first focused on what is the best for the organization and its purpose, not themselves. Level 5 leaders have various personalities, they are often self-effacing, quiet, reserved, and even shy. It has been identified that every good-to-great transition began with a Level 5 leader. Those motivated the organization more with inspired standards than inspiring personality. 
Other writers such as Soderholm (1989, p. 13) believes that leadership is about innovating new ideas and concepts that create desirable outcomes. To drive a change successfully entrepreneurship, innovation and creativity are required. The difference between leader and manager is; a leader is doing the right thing and manager's role is to do the things right. The situational leadership model main principle is that there is no single "best" style of leadership. The model believes that effective leadership is task driven and the most successful leaders are those who can adapt their leadership style to the performance readiness of the individual. Effective leadership varies depends on the person or group but also depends on the task that needs completing. The main two concepts of situational leadership are split into two categories:

1) Leadership style and individual.

2) Group's performance readiness level.

Mamood, Basharat, \& Bashir (2012, p. 512-522) propose that "leadership and management are interconnected and often people confuse those two terms". As such both were included in this research.

First studies looking at change from psychology and sociology point of view started with studies focusing on organizational development (OD). First roots of OD research are in the early work of Lewin (1946. P. 34-46). Lewin was a humanitarian and believed that human conditions can only be improved by first resolving conflicts (Burnes, 2004). His theories regulating human behaviour were then applied in studies focusing on organizational dynamics. This research confirmed that individual as well as group perspective influence how people react to organizational change (French \& Bell, 1995).

Engineering Management (EM) started research on change with Frederick Taylor, called the "father of management science", in 1911. Who introduced "Piece Rate System" which was focused on improving the efficiency of the shop floor operations? (Babcock \& Morse, 2002). Engineering management applies engineering values and skills in training people and managing projects (Lannes, 2001). Engineering management is essential in managing change.

Engineering management implements traditionally technical functions such as production and design to the managerial world (Omurtag, 2009) and by including human factor element it creates a unique position within other engineering disciplines. The definition for industrial engineering by the Institute of Industrial Engineering (IIE) is design, installation and improvement of systems and people, information, materials, equipment and energy.

Industrial engineering uses knowledge and skills from mathematical, physical, and social sciences point of view applying principles and methods of engineering analysis. This enables EM to specify and evaluate the outcomes effectively. Both EM \& IM are important to manage change, and by including human factor aspect gives them a unique position within engineering disciplines (Baker, 2009, p.9-12).

Figure 4 shows that each theory assumes it is possible to translate human actions correctly (Lovell, 1980), (Pavlov, 1960) and (Skinner, 1974). The oldest perspective is looking at group dynamics (Schein, 1969). Lewin 1946) in 1948 created group dynamics and he believed that since structures are becoming more team-based, then individual's behaviour is a function of the group environment and can only be modified in terms of groups.

As a result of merging both, individual and group perspectives the open systems perspective for organizational development has been created. This perspective looks at the organization from a broader point of view (Buckley, 1968,), (Scott, 1987). Lalonde believed that the open system requires an ongoing change to adapt to the forever changing environment and this creates a strategy for continues learning and get integrated into organizational culture (Habib \& Jamal, 2013: Kezar, 2001). 


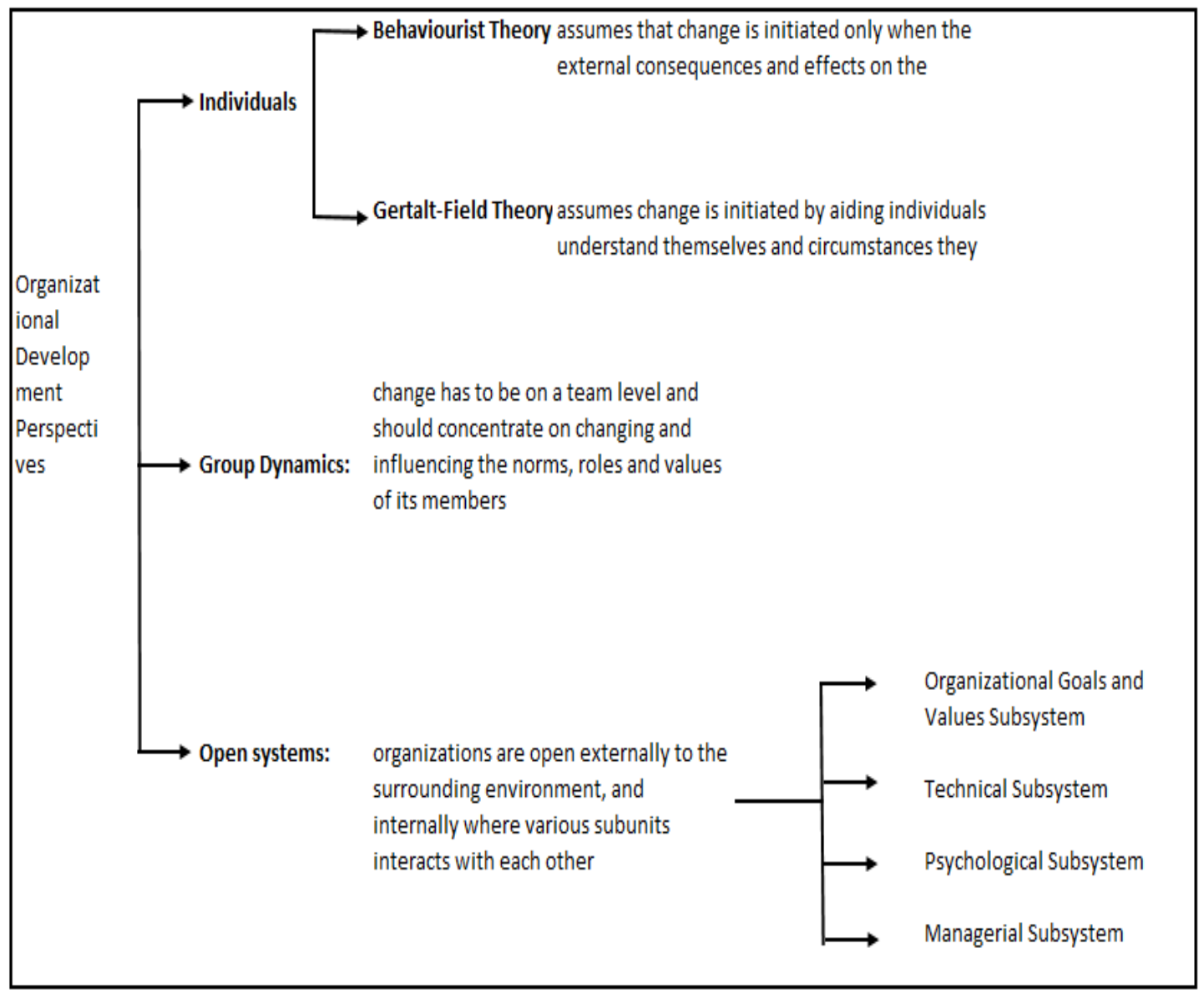

Figure 4 Organizational Development Perspective (Source: Own)

\section{Practical Reflection of Survey Data}

The differences between successful and unsuccessful organisational changes had an interesting outcome. Top three questions directly related to creative problem-solving change method and fair process (3 E's) as described by Alex Osborn in his book Wake Up your Mind. Emphasis is this method is put on the engagement of people in the organisational change and clearly defined scope of change. Forth most rated question was relating to soft skills a behaviours question relating to the attitude which again is closely connected to those methods.

1. Question 1 - Management - Was the purpose of the organisational project change clearly explained/defined?

2. Question 3 - Management - Were expectations of the organisational project change clearly set?

3. Question 6 - Behaviour - Did you feel engaged with the organisational project?

4. Question 4- Attitude- Were you empowered to raise your opinion?

All 4 top questions received overwhelming $90 \%$ which meant the respondents either strongly agreed or agreed in each of the four questions. This had a direct coloration on the results of the change as $98 \%$ of people either agreed or strongly agreed the goal of the project was achieved as listed in figure 5. 


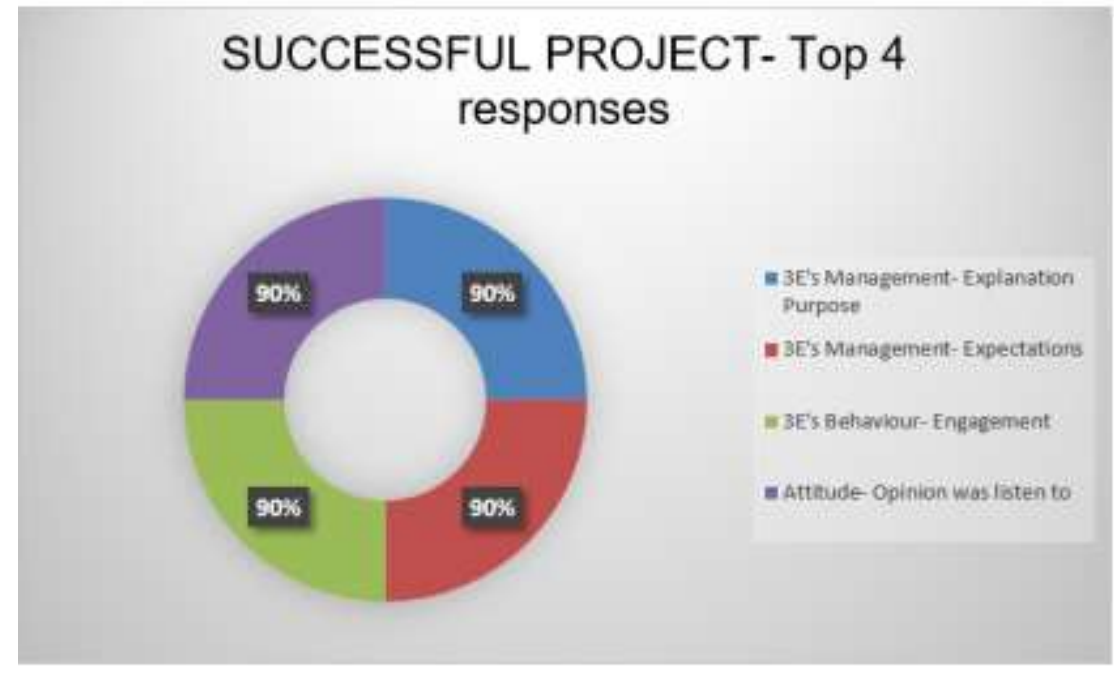

Figure 5 Top four response for the successful project (Source: Own)

In contrast, the 4 least scored questions for unsuccessful projects again had all three questions asking in relation to creative problem-solving method and 3 E's. Which in essence meant that the respondents felt in the unsuccessful organisational change example there was no engagement, clarity expectation or explanation.

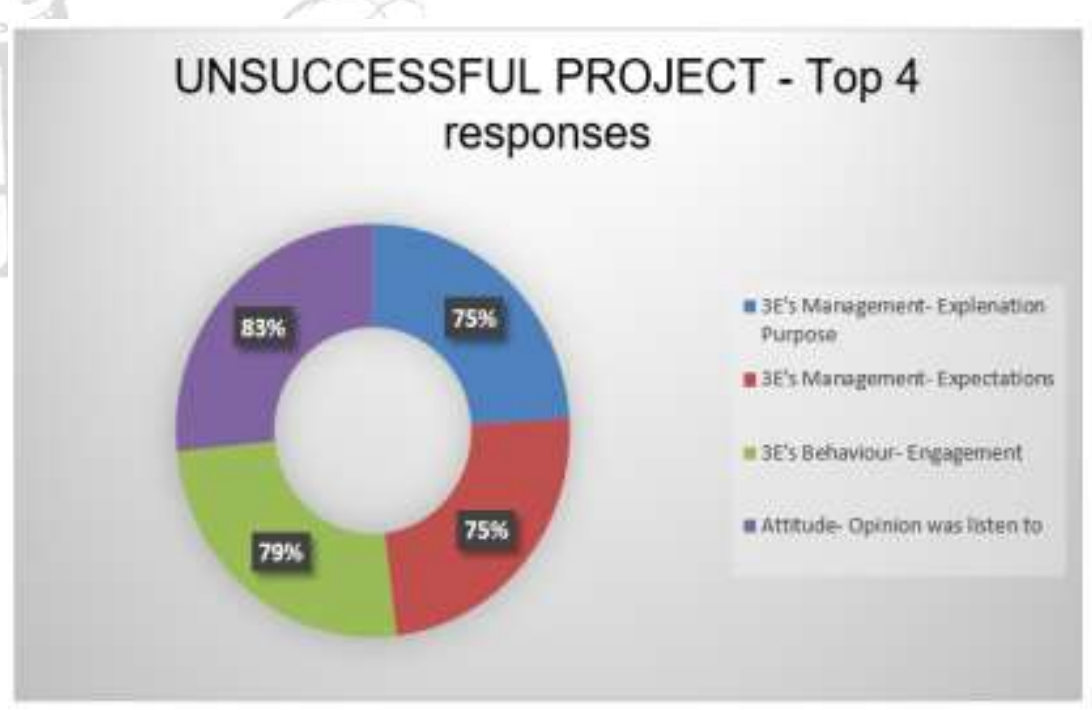

Figure 6 Least four response for Unsuccessful project (Source: Own)

Top four responses in both scenarios contained questions regards to explanation, expectations and engagement. For a successful project, the five highest score was relating to a question about empowerment. However, in the case of an unsuccessful project the five one was relating to opinion wasn't listen to the question. Nevertheless, both questions related to subcategory for attitude.

Figure 7 captures the correlation of project results such as project goal achieved and the top four responses. The charted clearly shows where lack of 3 E's we have seen the project not delivering the goal and actually $96 \%$ of participants said the project goal wasn't achieved. 


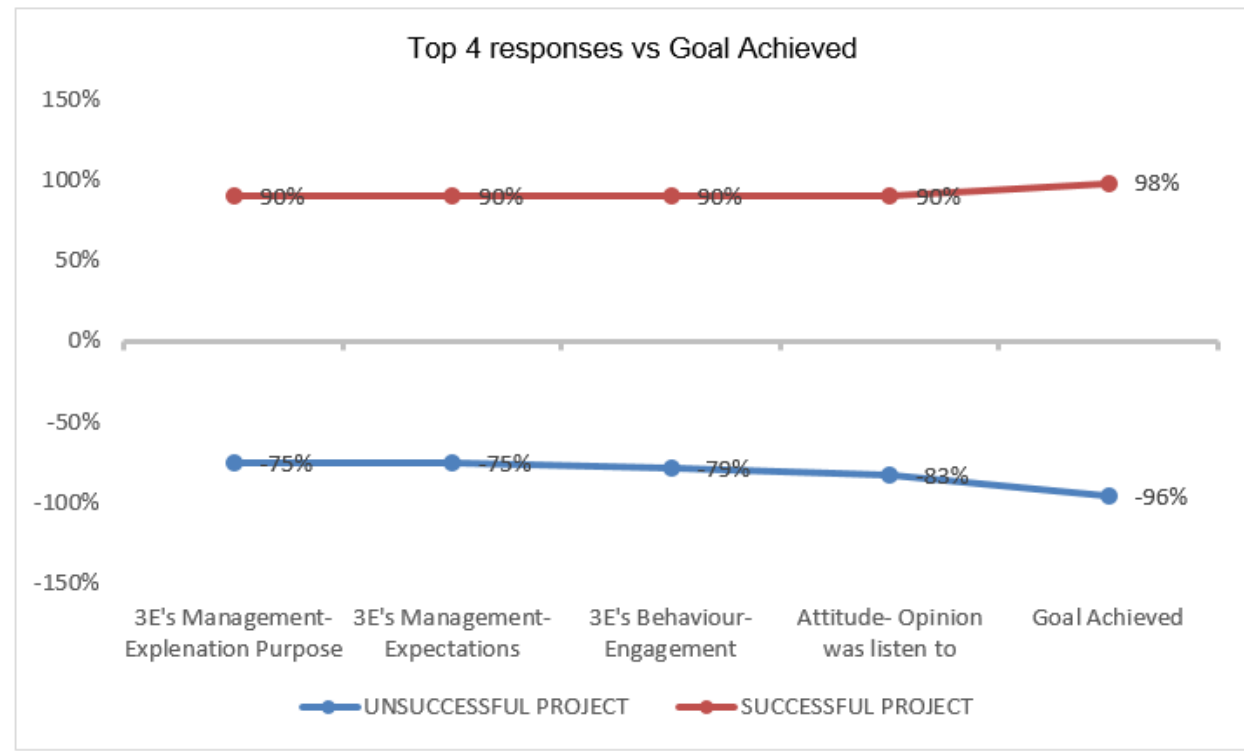

Figure 7 Top four responses vs Goal Achieved (Source: Own)

In successful change scenario, least valued question by the participants was budget at $60 \%$ only and interestingly the same outcome was replicated in the scenario for unsuccessful organisation change here it was $73 \%$ of respondents.

\section{Discussion}

To establish the validity of this research multiple data collection was used. Additionally to the survey's quantitative questions, one qualitative question was included at the end of the survey. Following chapter reviews and summarises the qualitative data collected in both surveys and interviews.

All validated 52 respondents answered the open-ended question. Interestingly we could see thirty people stated that for successful organisational change engagement or involvement with staff, people to listen to is necessary for achieving successful organisational change. Which matches the principle of ADKAR model which puts a strong emphasis on people's engagement and bottom-up approach. Where for example in Kotler's model feedback is not necessarily taken on board, therefore has a risk of people just doing what they get told to do.

\begin{tabular}{|l|l|}
\hline $\begin{array}{l}\text { Strengths } \\
\text { Focus on people } \\
\text { Set goals with a flexible model } \\
\text { Applicable to most of the situations }\end{array}$ & $\begin{array}{l}\text { Weaknesses } \\
\text { People saying they using fair process, but } \\
\text { they not really mean it- corruption of fair } \\
\text { process model }\end{array}$ \\
\hline $\begin{array}{l}\text { Opportunities } \\
\text { Speed of change } \\
\begin{array}{l}\text { Less disruptive } \\
\text { High success rate }\end{array}\end{array}$ & $\begin{array}{l}\text { Threats } \\
\text { A clear understanding of roles and boundaries }\end{array}$ \\
\hline
\end{tabular}

Figure 8 SWOT analyses ADKAR/ Fair Process- Survey (Source: Own)

It was fascinating and moving to feel the emotions and obtaining further information from the respondent, who were individually talking about their experience as stipulated in literature by Frels \& Onwuegbuzie (2013). A clear majority of the interviewees were indicating that people engagement is very important and 
found models such as creative problem solving or ADKAR model much more effective and successful. However, it was pointed out that one of the pitfalls of such approach was not having a direction from the leader as such.

\begin{tabular}{|l|l|}
\hline Strengths & Weaknesses \\
Better thinking & Lack of objective guidelines \\
Better risk handling & Not everyone is prepared to participate \\
Communication & Time constraints \\
Increased understanding & Lack of leadership in the sponsor role \\
A higher number of solutions & \\
Higher commitment from people & \\
Productivity outputs & \\
\hline $\begin{array}{l}\text { Opportunities } \\
\text { Higher commitment from people } \\
\text { Productivity outputs } \\
\text { Improved customer satisfaction }\end{array}$ & Threats \\
\hline
\end{tabular}

Figure 9 SWOT analyses ADKAR and Kotler's approach- Interview (Source: Own)

\section{Conclusion}

The data analysis completed in the chapter above lead to a number of conclusions as displayed in figure 10 .

\begin{tabular}{|l|l|}
\hline Conclusion 1 & Increase of using models which engage people relates to more successful change. \\
\hline Conclusion 2 & Clear definition of scope when managing change relates to more successful results. \\
\hline Conclusion 3 & $\begin{array}{l}\text { Sponsors role and organisational culture when managing change impacts the } \\
\text { success of the change. }\end{array}$ \\
\hline Conclusion 4 & $\begin{array}{l}\text { The bottom-up change models can be time-consuming and challenging for the } \\
\text { change group, however, have highly successful results. }\end{array}$ \\
\hline Conclusion 5 & $\begin{array}{l}\text { Traditional change models with top-down approach relate to less successful } \\
\text { change- which can have underlining issue such as staff morale. }\end{array}$ \\
\hline
\end{tabular}

$$
\text { Figure } 10 \text { Research Conclusions (Source: Own) }
$$

The paper research question was: "What is an effective model for successful organizational change and is fair process methodology that is based on engagement, explanation \& expectation clarity connected to successful organizational change?" The analysis completed above validated that effective models for successful organisational change are focused on engagement, explanation and expectation clarity. Participants in the interview also stressed the importance of individual roles in the change such as sponsor, resource group (project team) \& facilitator (project manager), which is important in the creative problemsolving model.

The two main lessons learned whilst preparing this paper research are:

1) Organisational change research is continuously evolving discipline.

2) The researcher should try to find available lessons learned in the literature before starting the research.

More specific lessons learned whilst preparing this paper fall into the following categories: 
1) Research Topic- choosing the right topic is pivotal and guides all subsequent phases. Although the overall objective of the research was established (successful organisational change) finding the link between organisational change models and its subcategories was difficult.

2) Literature review- labour intensive and time-consuming, however, today's' technology has enabled access to the required sources.

3) Research methodology- setting up a research methodology for this thesis required assessing research processes and techniques. Personally, I enjoyed selecting surveys where I got to use survey portal which I didn't have experience with before. Also completing personal interviews was a very fruitful exercise for me.

4) Data analysis part was definitely interesting but I also found challenging due to time constraints.

From the two examples at the face to face interviews we could see two organisational changes for Bureau Veritas were done using two different organisational change models whilst interviewee $\# 2$ described the top down approach similar to Kotter the interviewee \#3 had an experience with a model based on creative problem solving and fair process. We personally have been able to observe both of the changes and can confirm that the results of the change using creative problem solving was the one that was successful and drove an increase in operating profit, stabilisation of the division and reduction of reports backlog. Additionally, in scenario \#2 we have seen reduced productivity and staff morale and unfortunately a couple of the member's wellbeing from the management team has been also impacted, which personally for me is the biggest reason why I think model using creative problem solving and fair process are fundamentally necessary for achieving successful organisational change.

The context of the is research can be used for further research particularly focuses on the relationship of stakeholders roles (sponsor, resource group, facilitator) and how their views link to the perception of the success of the change. Face to face interviews also opened a question of potential research on the impact of unsuccessful change on people involved in the change. As concluded in chapter 4.2 based on the results from the analyses completed my clear recommendations to Bureau Veritas and other organisations are to use fair process.

The paper explores some of the common models that organisations adopt when implementing organisational change. Whilst organisations can (and often do) implement change without referencing any established model we wanted to improve our understanding of the key aspects that are important to ensure were in place before implementing an effective change project. Effectiveness will include delivering the change on time, within budget and delivering the benefits that were expected. It should also include ensuring that the people within the organisation are not impacted by the process and that in reality they develop and use their experience when involved in future change projects.

The results of this research identified the following aspects that must be in place and considered before embarking on the change project:

1. A Sponsor who has the authority and interest in the project.

2. An understanding of the culture and its impact on the project.

3. Clear Scope.

4. Clear timelines and milestones.

5. Clarity of the change and the measurable benefits.

6. Engagement of people who would be affected by the change.

7. Deployment of "Fair Process".

Many of the aspects referenced above are concerned about people, it is not the model that delivers effective change. It is the people who are engaged in the process. Ensuring these aspects are in place takes time, skill and sometimes are not easy to fulfil but if they have not to be addressed, achieving effective change will be compromised and the project will simply be one of the many that fail to deliver the benefits. There is also 
the possibility that the change if managed poorly will actually reduce the performance of the business. This will cause a negative impact on future change projects or hinder the appetite for change which would lead to the organisation stagnating and therefore put its future viability at risk.

\section{References}

Ackoff, R. L. (2006). Idealized design: How to dissolve tomorrow's crisis ... today. Philadelphia, PA: Wharton School Publishing.

Armenakis, A. A., \& Bedeian, A. G. (1999). Organizational change: A review of theory and research in the 1990s. Journal of Management, 25(3), 293-315.

Ashurst, C., \& Hodges, J. (2010). Exploring business transformation: The challenges of developing a benefits realization capability. Journal of Change Management, 10(2), 217-237.

Babcock, D. L., \& Morse, L. C. (2002). Managing engineering and technology: An introduction to management for engineers (3rd ed.). Upper Saddle River, NJ: Prentice Hall.

Baker, M. (2009). My involvement in engineering management during its pioneer years. Engineering Management Journal, 21(3), 9-12.

Balogun, J., \& Hope Hailey, V. (2004). Exploring strategic change (2nd ed.). London, England: Prentice Hall.

Bamford, D. R., \& Forrester, P. L. (2003). Managing planned and emergent change within an operations management environment. International Journal of Operations \& Production Management, 23(5), 546.

Beer, M., Eisenstat, R. A., \& Spector, B. (1990). Why change programs don't produce change. Harvard Business Review, 68(6), 158-166.

Buckley, W. F. (1968). Modern systems research for the behavioural scientist: A sourcebook. Chicago, IL: Aldine Publishing Co.

Bullock, R. J., \& Batten, D. (1985). It's just a phase we're going through: A review and synthesis of OD phase analysis. Group \& Organization Studies, 10(4), 383.

Burnes, B. (2004). Managing change:A strategic approach to organisational dynamics (4th ed.). Harlow, England: Prentice Hall.

Collins, J. (2011). Good to Great. US: Collins Business.

Covey, S. R. (1989). The 7 Habits of highly effective people: Free Press.

Creswell, J. W. \& Brown, M. L. (1992). How chairpersons enhance faculty research: A grounded theory study. Review of Higher Education, 16(1), 41-62.

Creswell, J. W., \& Miller, G. A. (1997). Research methodologies and the doctoral process. New Directions for Higher Education, (99), 33-46.

Crosby, P. B. (1984). Quality without tears: The art of hassle-free management. New York: McGraw-Hill.

De Feo, J. A. (2004). Breakthrough performance: A proven way out of a recurring predicament. Ivey Business Journal, 69(2), 1-11.

Dess, G. G., \& Picken, J. C. (2000). Changing roles: Leadership in the 21 st century. Organizational Dynamics, 28(3), 18-34.

Dillman, D. A., Smyth, J. D., \& Christian, L. M. (2009). Internet, mail, and mixed-mode surveys: The tailored design method. Hoboken, NJ: John Wiley \& Sons Inc.

Drucker, P. F. (1986). The practice of management. New York: Perennial Library.

Dunphy, D., \& Stace, D. (1993). The strategic management of corporate change. Human Relations, 46(8), 905-920.

Fayol, H. (1950). General and industrial management Pitman.

Frels, R. K., \& Onwuegbuzie, A. J. (2013). Administering quantitative instruments with qualitative interviews: A mixed research approach. Journal of Counseling \& Development, 91(2), 184-194.

French, W. L., \& Bell, C. (1995). Organization development: Behavioural science interventions for organization improvement (5th ed.). Englewood Cliffs, N.J.: Prentice-Hall.

Galpin, T. J. (1996). The human side of change: A practical guide to organization redesign. San Francisco, CA: Jossey-Bass Publishers. 
Green, S. B. (1991). How many subjects does it take to do A regression analysis. Multivariate behavioural Research, 26(3), 499.

Grover, V. (1999). From business reengineering to business process change management: A longitudinal study of trends.. IEEE Transactions on Engineering Management, 46(1), 36.

Gunasekaran, A., \& Kobu, B. (2007). Performance measures and metrics in logistics and supply chain management: A review of recent literature (1995-2004) for research and applications. International Journal of Production Research, 45(12), 2819-2840.

Habib, M. N., Jamal, W., \& Manzoor, H. (2018). Exploring the Process of Organizational Change in Driving Licensing Authority; A Case Study. City University Research Journal, 8(2), 127-142.

Habib, M. N., Jamal, W., \& Manzoor, H. (2018). Exploring Organizational Change in Public Sector of Pakistan through Thematic Networks. Abasyn Journal of Social Sciences, July, 18 (AICTBM-18, Special Issue), 9-19..

Habib, M. N., \& Jamal, W. (2014). An Effort towards a Common Model for Organizational Change: Synergizing Tools and Processes for Change. Business \& Economic Review, 06(2), 1-26.

Habib, N. M., \& Jamal, W. (2013). Business Process Reengineering (BPR) Initiatives in Public Sector of Pakistan. Business and Economic Review, 5(1), 89-151.

Habib, N. M., \& Wazir, I. M. (2012). Role of Education and Training in the successful implementation of Business Process Reengineering: A case of public sector of Khyber PakhtunKhwa. World Journal of Social Sciences, 2(2), 172-185.

Hackett, G. (1981). Survey research methods. Personnel \& Guidance Journal, 59(9).

Haidar, E. (2006). Leadership and management of change. Journal of Community Nursing, 20(4), 13.

Hamel, G. (2000). Leading the revolution. Boston, MA: Harvard Business School Press.

Holweg, M. (2007). The genealogy of lean production. Journal of Operations Management, 25(2), 420437.

Ittner, C. D., \& Larcker, D. F. (1998). Innovations in performance measurement: Trends and research implications. Journal of Management Accounting Research, 10, 205-238.

Juran, J. M., (1962). Quality control handbook. New York: McGraw-Hill.

Kanter, R. M., Stein, B., \& Jick, T. (1992). The challenge of organizational change: How companies experience it and leaders guide it. New York: Free Press; Toronto: Maxwell Macmillan Canada; New York: Maxwell Macmillan International.

Kezar, A. J. (2001). Understanding and facilitating organizational change in the $21^{\text {st }}$ century:Recent research and conceptualizations. ASHE-ERIC Higher Education Report, 28(4), 1.

Kim, W.Ch, Mauborgne, A. (1997), Managing in the knowledge Economy, Best of HBR.

Kotter, J. P. (1996). Leading change. Boston, MA: Harvard Business School Press.

Kouzes, J. M., \& Posner, B. Z. (1995). The leadership challenge: How to keep getting extraordinary things done in organizations. San Francisco, CA: Jossey-Bass.

Kraut, A. I. (1996). Organizational surveys: Tools for assessment and change. San Francisco, CA:

Lannes, W. J. (2001). What is engineering management? IEEE Transactions on Engineering Management, 48(1), 107.

Leedy, P. D., \& Ormrod, J. E. (2001). Practical research: Planning and design. Upper Saddle River, N.J: Merrill Prentice Hall.

Leedy, P. D., \& Ormrod, J. E. (2005). Practical research: Planning and design. Prentice Hall. Upper Saddle River, N.J: Merrill Prentice Hall.

Lewin, K. (1946). Action research and minority problems. Journal of Social Issues, 2(4), 34-46.

Linderman, K., Schroeder, R. G., \& Choo, A. S. (2006). Six sigma: The role of goals in improvement teams. Journal of Operations Management, 24(6), 779-790.

Lovell, R. B. (1980). Adult learning. London; New York: Croom Helm; Halsted Press.

Mader, D. P. (2008). Lean six sigma's evolution

Mahmood, Z., Basharat, M., \& Bashir, Z. (2012). Review of classical management theories. International Journal of Social Sciences \& Education, 2(1), 512-522.

Moen, R. D., \& Norman, C. L. (2010). Circling back 
Moran, J. W., \& Brightman, B. K. (2001). Leading organizational change. The Career Development International, 6(2), 111-118.

Neave, H. The Deming Dimension: Tennessee, SPC Press, 1990, p. 119.

Neves, P., \& Caetano, A. (2009). Commitment to change: Contributions to trust in the supervisor and work outcomes. Group \& Organization Management, 34(6), 623.

Northouse, P. G. (2007). Leadership theory and practice. Thousand Oaks, CA: Sage Publications, Inc.

Omurtag, Y. (2009). What is engineering management? A new look at an old question. Engineering Management Journal, 21(4), 3-6.

Pavlov, I. P. (1960). Conditioned reflexes; an investigation of the physiological activity of the cerebral cortex. Translated. New York: Dover Publications.

Rouse, W. B. (2011). Necessary competencies for transforming an enterprise. Journal of Enterprise Transformation, 1(1), 71-92.

Schein, E. H. (1969). Process consultation. Reading, MA: Addison-Wesley Publishing Co.

Scott, W. R. (1987). Organizations: Rational, natural, and open systems. Englewood Cliffs, N.J.: PrenticeHall.

Shewhart, W. A., \& Deming, W. E. (1945). Statistical method from the viewpoint of quality control by walter A. shewhart with the editorial assistance of W. Edwards deming. Washington: The Graduate school, The Department of agriculture.

Singh, A., \& Shoura, M. M. (2006). A life cycle evaluation of change in an engineering organization: A case study. International Journal of Project Management, 24(4), 337-348.

Sink, D. S. (1985). Productivity management: Planning, measurement and evaluation, control and improvement. New York: Wiley.

Sink, D. S., \& Tuttle, T. C. (1989). Planning and measurement in your organization of the future. Norcross, GA: Industrial Engineering and Management Press.

Sink, D. S., Johnston, C. S., \& Morris, W. T. (1995). By what method? Are you, developing the knowledge and skills to lead large-scale quality. Norcross, GA: Industrial Engineering and Management Press: Institute of Industrial Engineers.

Skinner, B. F. (1974). About behaviourism. New York: Knopf.

Soderholm, L. G. (1989). Needed: Engineering leadership. Design News, 45(13), 13.

Thompson, J. D. (1967). Organizations in action; social science bases of administrative theory. New York: McGraw-Hill.

Womack, J. P., \& Jones, D. T. (2003). Lean thinking: Banish waste and create wealth in your corporation. Free Press.

Wouters, M., \& Sportel, M. (2005). The role of existing measures in developing and implementing performance measurement systems.

Zook, C. (2007). Finding your next CORE business. Harvard Business Review, 85(4), 66-75. 